\title{
MONUMENTOS CONFRONTADOS: NUEVOS ROLES PARA EL PATRIMONIO ANTE LOS DESENCUENTROS SOCIALES
}

Monumentos enfrentados: novos papéis do patrimônio diante das desavenças sociais

Confronted monuments: new roles for heritage

in the face of social disagreements

Yúmari Pérez Ramos

Profesor de Tiempo Completo, Facultad de Arquitectura. Universidad Nacional Autónoma de México. Ciudad de México, México.

yumaripr@unam.mx

https://orcid.org/0000-0001-9043-7414

\section{Diana Ramiro Esteban}

Coordinadora del Programa de Maestría y Doctorado en Arquitectura, Facultad de Arquitectura. Universidad Nacional Autónoma de México. Ciudad de México, México. ramiroed@hotmail.com

https://orcid.org/0000-0001-7592-5962

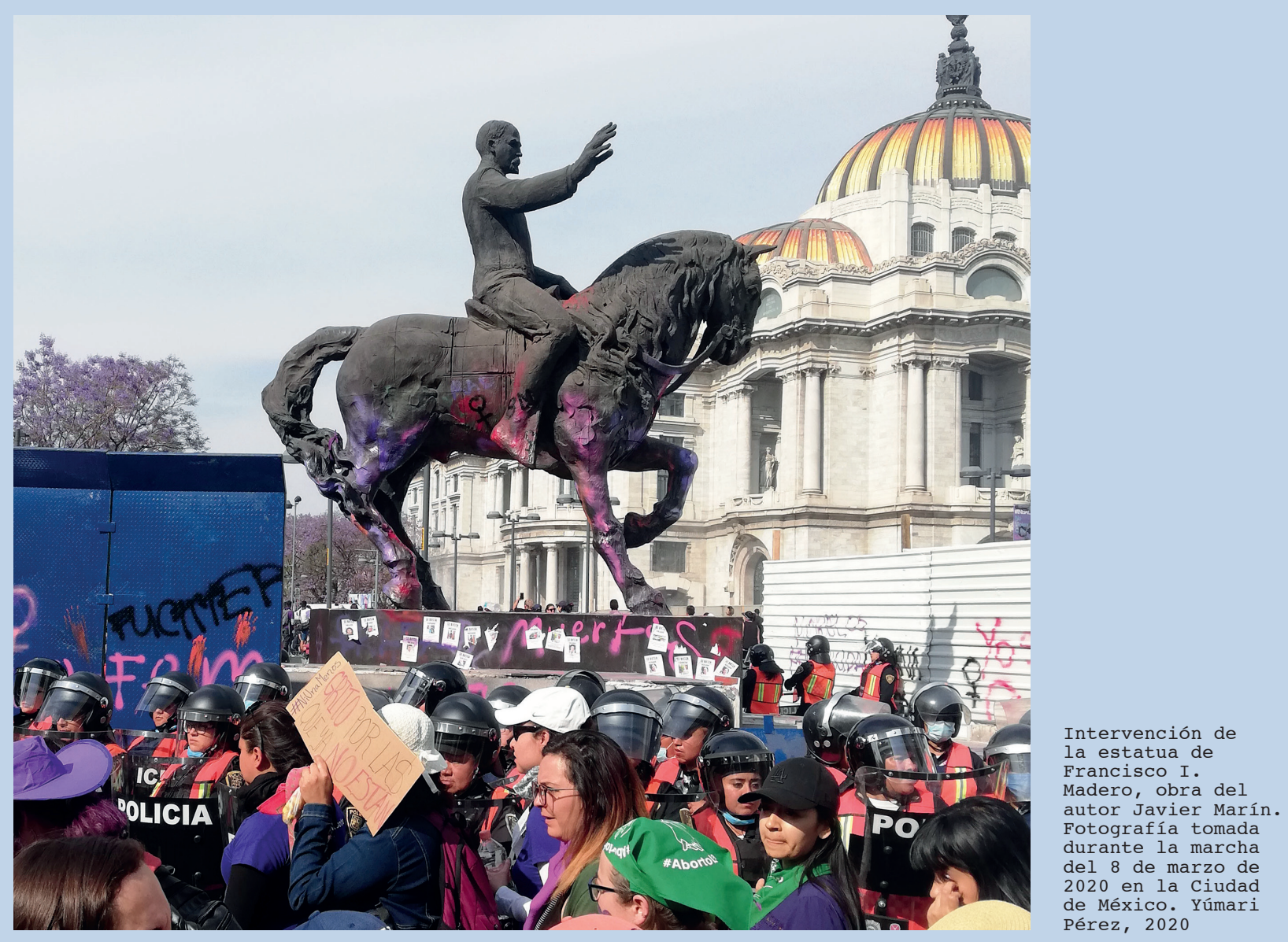




\section{RESUMEN}

La agresión a monumentos — pintas', mutilaciones, derribos-, que se han visto recientemente en todo el mundo, no puede pasar desapercibida para los estudiosos del patrimonio. Es un fenómeno que anuncia la obsolescencia de ideas y teorías adoptadas hasta ahora sobre el patrimonio y su conservación. A lo largo del trabajo se reflexiona en torno al patrimonio como herencia cultural, y se explica cómo los monumentos conmemorativos difieren de los monumentos históricos, un asunto que adquiere centralidad cuando se habla de museificación y petrificación del patrimonio. Para situar este fenómeno en la realidad, se abordan tres situaciones de asalto a monumentos — la marcha del 8 de noviembre de 2018 en Santiago de Chile, el derribo de estatuas en EUA e Inglaterra dentro del movimiento Black Lives Matter y el movimiento \#NoMeCuidanMeViolan en México-. La reflexión es en torno a las motivaciones que llevan a estas actuaciones sobre el patrimonio, a las reacciones que se generan de parte de los grupos hegemónicos y, más que nada, en cuanto a las resignificaciones y redefiniciones que se van dando o pudieran darse, a partir de todo esto, sobre el patrimonio cultural.

Palabras Clave: monumentos, patrimonio cultural, teoría de la restauración, movimientos sociales, memoria

\section{RESUMO}

O ataque a monumentos — pinturas, mutilações, demolições - recentemente vistos em todo o mundo, não pode passar despercebido aos estudiosos do patrimônio. É um fenômeno que anuncia a obsolescência das ideias e teorias até então adotadas sobre o patrimônio e sua conservação. Ao longo da obra, é refletida sobre o patrimônio como patrimônio cultural, e é explicado como os monumentos comemorativos se diferenciam dos monumentos históricos, questão que adquire centralidade quando se fala em museificação e petrificação do patrimônio. Para colocar este fenômeno em realidade, três situações de assalto a monumentos são abordadas — a marcha de 8 de novembro de 2018 em Santiago do Chile, a demolição de estátuas nos Estados Unidos e na Inglaterra dentro do movimento Black Lives Matter e o movimento \#NoMeCuidanMeViolan no México- o último é tratado de forma mais extensa. A reflexão gira em torno das motivações que levam a essas ações sobre o patrimônio, das reações que se geram por parte dos grupos hegemônicos e, mais do que tudo, quanto às ressignificações e redefinições que estão ocorrendo ou que poderiam ser atribuídas a partir de tudo isso no patrimônio cultural.

Palavras Chave: monumentos, patrimônio cultural, teoria da restauração, movimentos sociais, memória

\section{ABSTRACT}

The attacks on monuments — street $\mathrm{art}^{2}$, mutilations, being brought down - that have been seen around the world recently, cannot go unnoticed by heritage academics. It is a phenomenon that heralds the obsolescence of ideas and theories adopted so far on heritage and its conservation. Throughout this work, reflections are made about heritage as cultural heritage, explaining how commemorative monuments differ from historical monuments, a topic that comes under the limelight when talking about museification and petrification of heritage. To give context to this phenomenon, three attacks on monuments are addressed the march of November $8^{\text {th }}, 2018$ in Santiago de Chile, when people brought down statues in the US and England within the Black Lives Matter movement and the \#NoMeCuidanMeViolan movement, in Mexico. The reflection considers the motivations behind these actions against heritage, the reactions of hegemonic groups and, more than anything, the resignifications and redefinitions that are taking place or could take place, as a result of all this, about cultural heritage.

Keywords: monuments, cultural heritage, restoration theory, social movements, memory

1 Utilizamos a lo largo del texto la palabra pinta para referirnos a la pintura libre, considerada ilegal, que se realiza en las superficies de inmuebles y monumentos escultóricos ubicados en espacios públicos. En algunos países es sinónimo de graffiti, pintada y rayones.
2 We use the word street art throughout the text to refer to free painting, considered illegal, that is made on the surfaces of properties and sculpted monuments located in public spaces. In some countries, this is a synonym of graffiti, murals and tags. 


\section{INTRODUCCIÓN}

\section{PATRIMONIO, MONUMENTOS Y MONUMENTOS HISTÓRICOS}

Los monumentos son fundamentalmente elementos que resguardan el pasado para trasladar un mensaje al presente, sirven para que ese ayer no se pulverice con el paso del tiempo, sino que se conserve un sentido vigente en el ahora, con adición de una estética inherente, haciendo que las piedras y metales transmitan la idea de belleza y aleccionen a la sociedad sobre el pasado. Sin embargo, llega el momento en que esas cualidades propias del monumento cambian su significado para la sociedad y surgen cuestionamientos sobre su relación con esta herencia. Aquello para lo que ese "ahora monumento" fue creado, en otro tiempo y otra sociedad, necesita replantearse constantemente ante los escenarios sociales actuales y sus problemas, para validar su significado y sentido identitario o convertirse en objeto y sujeto de la manifestación de los descontentos.

Esta metamorfosis en la vinculación sociedad-patrimonio está manifiesta en muchos de los monumentos que forman parte del contexto urbano, en el espacio público que desde un punto de vista de la filosofía política se asocia con la esfera pública o reunión de personas que fiscalizan el ejercicio del poder y se pronuncian sobre asuntos concernientes a la vida en común (Delgado, 20l I), pues permite un espacio de visibilidad generalizada. La agresión a los bienes patrimoniales como forma de protesta por las injusticias que se padecen en cada nación no es nueva, pero no habían detonado con la fuerza y el modo en que se fueron presentando en el último año.

Se ha observado, en estas formas, que el patrimonio juega un nuevo papel, este se convierte en un acontecimiento, por los actos en sí, o en un telón de fondo que sirve como soporte para hacer evidentes las demandas de quienes se expresan en búsqueda de esta visibilidad; este uso del patrimonio se vuelve a su vez una limitante para comunicar la legitimidad de las protestas, por la manera en que los medios oficiales exponen los hechos. El dilema es hacia dónde llevar ese discurso, al punto medio o a los extremos radicales, por ello cabe cuestionarse cuál es el significado del patrimonio y desde dónde se significa, para cavilar si hay una nueva función adquirida para los monumentos, y si pueden llegar a considerarse artefactos útiles para declarar, exponer y evidenciar los mensajes emergentes de las sociedades actuales.

El significado, el alcance, la interpretación y la delimitación del patrimonio son cuestiones de discusión permanente que se van aterrizando en posiciones mutantes, en busca de adaptarse a la situación social prevaleciente.

Se dice que el patrimonio está intrínsecamente ligado a los desafíos más urgentes a los que se enfrenta toda la humanidad, pues a través suyo se busca una representación colectiva, lo que obliga a cuestionarse cuáles son los cánones de esa representatividad, quiénes son aquellos que la promueven y delimitan, qué es patrimonio y qué no y cómo se puede hacer uso del mismo. El patrimonio cultural es un recurso de cohesión social, que puede ser 
aprovechado en algunas sociedades como herramienta política, de reivindicación social y como elemento de lucha, y que es utilizado para construir y resignificar identidades. Pero ¿qué pasa cuando esa memoria deja de ser importante, cuando cae en el desinterés y así el artefacto memorable deja de ser un recurso de identidad, un signo de pertenencia?

Como se sabe, patrimonio es una acepción polisémica que adquiere significados particulares según el ámbito en que se utiliza. Para la UNESCO, organización que opera como foro mundial de discusión y difusión de la educación, la cultura y la ciencia, el patrimonio cultural es simultáneamente un producto y un proceso "que suministra a las sociedades un caudal de recursos que se heredan del pasado, se crean en el presente y se transmiten a las generaciones futuras para su beneficio" (20 I4). En esta concepción dinámica, alejada de la retórica de la nostalgia por el pretérito, es posible entender al patrimonio como recurso y a su vez, como proceso vivo, en contraste con visiones que insisten en caracterizarlo como algo inamovible. La propuesta es transitar hacia otra concepción de los bienes culturales, tangibles o intangibles, dejar de verlos como residuos de un tiempo pasado que haya que conservar en un supuesto modelo ideal, y mucho menos cuando hablamos de las manifestaciones vivas, que se reproducen continuamente en un concurso de formación permanente.

Es mediante las manifestaciones patrimoniales significativas que la gente recuerda y reconoce su pertenencia a un grupo social y a una comunidad; si bien la identidad cultural no es sólo una, sino múltiple, y siempre relacional y contextual; es decir, dinámica y procesual (Marcos, 20 l0). El patrimonio, una especie de simbología social para el mantenimiento y la transmisión de la memoria colectiva, está constituido por los bienes representativos de cada sociedad.Y se puede afirmar que esos bienes patrimoniales revisten una triple dimensión: física, social y mental; es decir, material y simbólica.

La palabra monumento y la acepción de monumento histórico remiten aún más a una idea estratificada de los bienes culturales, son precedentes de las concepciones actuales sobre el patrimonio. En el siglo XIX, y todavía a mediados del XX, la noción de monumento se refería a los bienes materiales del pasado que merecían conservarse. Françoise Choay, en su emblemático libro Alegoría de patrimonio, expone la relación directa de los monumentos con la memoria, que identifica con su original latino: monumentum, derivado a su vez de monere, - advertir, recordar - . Así, el monumento tiene la capacidad de suscitar, a través de la emoción, un recuerdo vivo, un pasado invocado y convocado. Se trata, finalmente, de todo artefacto que sirve a una comunidad para recordarse a sí misma y para que las generaciones venideras recuerden personas, eventos o creencias; actúa sobre la memoria, la moviliza desde la afectividad; evoca un pasado que lejos de ser cualquiera, ha sido escogido con fines vitales, en la 
3 Esta obra fue publicada en 1903; en ella se sintetizan los conceptos y principios definitorios sobre los monumentos, tal como se entendieron en el siglo XX medida en que sirve para invocar a la identidad de una comunidad. (Choay, 2007)

Alois Riegl, en su ya centenaria obra El culto moderno a los monumentos ${ }^{3}$ se ocupó de establecer la distinción entre monumento y monumento histórico. Al primero lo definió como una creación intencionada, que surgió en busca de satisfacer ciertas necesidades prácticas o ideales particulares; en contraste, el monumento histórico es una creación no intencionada (Riegl, 1903). Siguiendo la teoría riegliana, Choay abunda en la caracterización del monumento histórico: "no ha sido inicialmente deseado (ungewollte) ni creado como tal; se constituye como tal a posteriori, por las miradas convergentes del historiador y del aficionado que lo seleccionan entre la masa de edificios existentes en la cual los monumentos representan una pequeña parte" (2007).

En cuanto a la conservación y perdurabilidad de los monumentos, la misma autora habla del olvido, del desinterés y de la obsolescencia, que terminan por orillarles a su desaparición. También refiere a la destrucción voluntaria, negativa, y que se da por motivos religiosos, políticos o ideológicos. En cambio, los monumentos históricos, a pesar o tal vez debido a que son asumidos como tales de manera impositiva y a posteriori, reciben otras garantías para su conservación y permanencia: "Por el contrario, en la medida en que se inserta en un lugar inmutable y definitivo en el conjunto objetivado e inmovilizado por el saber, el monumento histórico exige, conforme a la lógica de ese saber y -al menos en teoría- su conservación incondicional" (Choay, 2007). Esta idea sirve para aproximarse a una primera explicación de por qué la agresión deliberada a ciertos monumentos históricos causa tanto malestar: ocurre que se percibe como un acto inaceptable porque pone en crisis la certeza de que los monumentos históricos son bienes inmutables y perpetuos, referentes históricos de un pasado objetivado, cuya existencia está condicionada a su propia integridad material.

Cuestionar la idea modélica y petrificada con la que frecuentemente se caracteriza al patrimonio resulta ciertamente incómodo para la mayoría, igual para los grupos hegemónicos que para los especialistas del pasado o para amplios sectores de la sociedad, que ven en esos monumentos un recurso de identidad; en todo momento el dictado es la conservación casi unidireccional. Es un tema que produce exaltación, pues permanentemente y en infinitas circunstancias, el patrimonio cultural se presenta en peligro de desaparición, creando gran alarma: turismo, desarrollo urbano, mercantilización, comunicación masiva, entre otros.

En la actualidad, se debiera repensar el patrimonio, no como una estructura jerárquica que se impone por parte del Estado, sino como una herencia cultural que no necesariamente se tiene que proteger, sino que se debe de entender desde ese sentido inicial, un 
EL PATRIMONIO

CULTURAL ANTE LOS MOVIMIENTOS SOCIALES elemento que representa a la sociedad de una época, pero también que la transita. Así es que los valores que se depositan en el patrimonio no pueden ser permanentes e inalterables, y ahora menos que nunca, cuando se resignifica de manera constante debido a la fuerte influencia del turismo, del comercio, de las migraciones y de los medios masivos de comunicación (Arizpe, 2000).

Así mismo, el monumento busca ser patrimonio cultural, a partir de reunir valores excepcionales y de identificación colectiva, que se fijen en una cuestión material, esta conexión forma parte de la identidad cultural, que se puede definir como un conjunto de valores, tradiciones, símbolos, creencias y modos de comportamiento que actúan como cohesionadores en un grupo social (González-Varas, 20।4), estas características para seguir en el presente debieran estar ligadas como un concepto ideológico en la sociedad actual, pero en este proceso de asociación "intervienen decisivamente la relectura y la resignificación de la historia y de la memoria" (González-Varas, 20l4) que en una primera instancia funcionan para la formación de una doctrina nacional, pero también influyen en las identidades de grupos marginados, que en algunos casos comienzan a ser mayoría, es en este momento en que el significado simbólico del monumento puede entrar en confrontación.

Como un fenómeno globalizado, en tiempos recientes, y cada vez con más frecuencia y con mayor difusión, se suscita la agresión a bienes patrimoniales, particularmente a monumentos históricos, como parte de actos de protesta de determinados grupos sociales que han sido agraviados por el Estado. Ciertamente, en muchos casos se trata de actos vandálicos, pero hay otros aspectos en los que conviene dar más atención, intentar comprenderlos en su fondo y no solo en su forma, antes de emitir la opinión estándar de que son procederes incorrectos.

La cobertura mediática de estos hechos sigue un patrón que prefiere enfatizar las pintas y amenazas a la integridad de los monumentos en lugar de reflexionar y comunicar los motivos del evento. Titulares de ejemplo: "Pintas a monumentos históricos son una agresión a todos, dice Gutiérrez Müller" (Revista Proceso, 27 de agosto de 20 19)"; "Olvido, pintas y ambulantaje ponen en riesgo el patrimonio cultural de Oaxaca”" (El imparcial, 3 I de julio de 2019); “Estallido social: Marchas, vandalismo y destrucción en Chile para que renuncie Sebastián Piñera (Diario.com, Miami, 10 de noviembre de 2019)". Todos estos encabezados y su contenido prefieren enfocar la atención del lector en el efecto visual, desconsiderando otros aspectos que desde una óptica de los derechos humanos es más trascendental: la exigencia de una sociedad, los motivos de la marcha, las demandas que señalan abusos e injusticias.

Este es un fenómeno que se ha ido extendiendo a lo largo del mundo, con mayor claridad en América y Europa; posiblemente no 
TRES MOVIMIENTOS

SOCIALES DE CONFRONTACIÓN CON LOS MONUMENTOS haya un país que no padezca pintas y destrucciones en sus monumentos históricos. Se trata de una consecuencia de la globalización, un proceso que, como explica García Canclini, se sustenta en el neoliberalismo, el cual intenta impregnar de manera global y uniforme todas las esferas de la vida social, política y cultural de las sociedades actuales (2009), con consecuencias lamentables para el bienestar de una inmensa mayoría de los ciudadanos, que quedan marginados a la pobreza y excluidos del bienestar social. Los desencuentros sociales son una de las resultantes del sistema neoliberal en el que estamos insertos; la desigualdad económica y por tanto social, están presentes en el día a día de nuestros contextos. ¿Cómo manifestarse? ¿Cómo lograr que los dirigentes y los grupos hegemónicos volteen a ver los descontentos, las situaciones de abuso, la violencia? Desde gente marchando desnuda hasta consignas escritas en muros y pisos o esculturas tiradas abajo, las demandas ciudadanas parecen tener más peso en donde son más visibles y se hacen más significativas, en muchas ocasiones su connotación es evidentemente provocadora.

De entre los muchos eventos de protesta con agresión a los monumentos que se han ido multiplicando en los últimos años, hemos escogido tres que a continuación presentamos y discutimos. Dos de los movimientos de los que hablaremos son particulares del contexto latinoamericano —Chile y México- y un tercero surgió en EUA, con especial eco en otros países anglosajones. Se trata de tres movimientos ampliamente conocidos, recientes e icónicos en cuanto a la agresión a los monumentos en consecuencia a movimientos sociales; no ahondaremos en su descripción o caracterización, tampoco interesa una reconstrucción de los hechos, lo que se busca es comprender este fenómeno desde la conceptualización del patrimonio cultural y su conservación, así como desde nuestra mirada, como actores sociales. Lejos de estar de acuerdo con las pintas y otras actuaciones adversas a la integridad de los bienes culturales, ni con ningún acto de violencia, lo que se busca es iniciar una discusión que abone en la construcción de posiciones que, como gremio y sociedad, nos lleven a cuestionarnos sobre el papel de patrimonio en los contextos de conflictos presentes, posiblemente estableciendo nuevas nociones y definiciones del mismo y el nuevo papel que podrán tener o ya tienen en las sociedades actuales. La idea cómoda y funcional de que el patrimonio es un recurso de identidad, reconocido y significativo para todos, está en crisis.

En Chile, el 18 de octubre de 2019, se desató una crisis social, por un profundo malestar en los ciudadanos chilenos, detonado por el incremento del precio del metro, que sacó a la luz un sentimiento de abuso, derivado de un modelo económico que no cumple con una sociedad justa. El viernes 8 de noviembre siguiente se concentró una marcha en la Plaza Italia, ubicada en Santiago de Chile y, a pesar de que había mucha gente alegre, volvieron a ocurrir actos 
4 https://actualidad.rt.com/actualidad/333079-perdida-gigantesca-incendio-universidad-chile de vandalismo como saqueos; también fue incendiada la sede de la Universidad Pedro de Valdivia, un edificio patrimonial construido en 1915 [Figura I]. El rector de la UPV, Rafael Rosell, informó que el lugar fue vandalizado desde la tarde y lamentó en un video lo que interpretó como una "pérdida gigantesca" para Chile y para "la educación superior chilena", que a su decir vulneró "el derecho" a estudiar. En este discurso se deduce que las autoridades usan alevosamente la idea de que el patrimonio significa e importa de igual manera para todos, como si la pérdida de un edificio significara la vulneración del derecho a la educación que, dicho de paso, era un tema principal en la protesta. ${ }^{4}$

Esta marcha incentivó el reclamo ciudadano en las calles, exigiendo cambios contundentes y profundos en las áreas de salud, educación y pensiones. En las pintas se alcanza a leer "fuera la prensa burguesa", "dejen de mentir", "no son 30 pesos, son 30 años", demandas plasmadas tanto en edificios patrimoniales como en los edificios con funciones gubernamentales. En este caso nos preguntamos iexiste un sentido de apropiación de la herencia cultural, o

Figura 1

Incendio en la

Universidad Pedro de

Valdivia.

Fuente: Reuters 2019

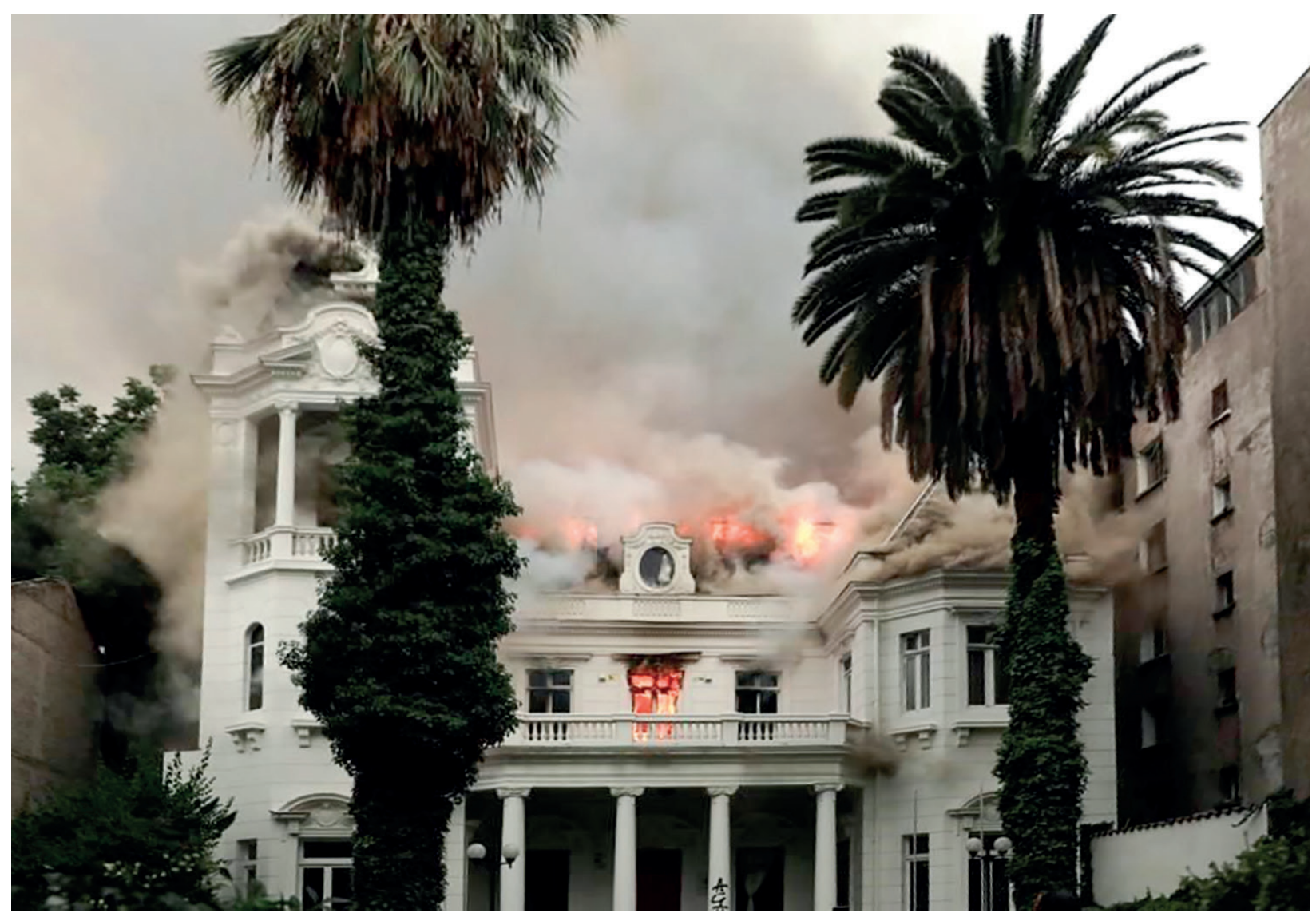

AS / Vol. 38. No58 / JULIO 2020 // ISSN impresa 07 16-2677 / ISSN digital 0719-6466 
es este el mejor lienzo para manifestarse porque se alcanzan más conciencias, porque toca a más gente? y si no, seguro incomoda más en general. Nadie haría rayones, pintas o destrozos en la fachada de su propia casa para hacer un reclamo, lo haría en la del contrincante. ¿Será entonces que los reclamantes no ven como suyos estos edificios? ¿No les dice nada su etiqueta de bienes patrimoniales? ¿Los interpretan como representaciones del Estado y de sus políticas? ¿Acaso ven en ellos un signo de la desigualdad que se padece?

Según notas periodísticas, a partir del estallido social en Chile y hasta enero de 2020, se cuentan 329 monumentos dañados, especialmente en Santiago y en Valparaíso, esculturas en calles y plazas usados como lienzos para las proclamas: "Las obras casi desaparecen detrás de decenas de rayados, pintadas de aerosol o elementos adheridos". En La Serena, ciudad al norte de Santiago, los manifestantes incendiaron y derribaron una escultura de Francisco de Aguirre, conquistador español del siglo XVI, para colocar en el mismo pedestal un busto escultórico, de materiales provisorios, de una mujer indígena del pueblo diaguita, a quien dieron el nombre de Milanka.

En otro contexto, el derribo y mutilación de esculturas ha sido la manifestación principal de movimiento black lives matter, que tomó gran fuerza a partir del asesinato del afroamericano George Floyd, el 25 de mayo de 2020, a manos de un policía en Minneapolis, E.U.A. Una vez que se hicieron públicos los videos del vergonzoso acto criminal, se inició una inmensa protesta, se habla de hasta 26 millones de estadounidenses que salieron a las calles. Este es el movimiento más grande de la historia de los E.U.A. (Larry Buchanan, Quoctrung Bui y Jugal K. Patel, 2020). Pocos días después, el 7 de junio en Bristol, Inglaterra, la estatua de bronce de Edward Colston, un esclavista del s. XVII, fue derribada y tirada al río, después de ello, decenas de estatuas asociadas a la esclavitud y al colonialismo fueron decapitadas, tiradas o quemadas. En Estados Unidos, en el día conmemorativo del fin de la esclavitud ocurrió otra ola de protestas contra el racismo, que actuó con pintas y derribes de las estatuas de los fundadores de ese país [Figura 2].

Por último, el movimiento feminista \#NoMeCuidanMeViolan, que ha causado gran revuelo en México y que ha sido fuertemente confrontado a partir del status quo con el que se define al patrimonio cultural, que los asume como intocable, al que todos debemos respetar. La primera marcha de este movimiento sucedió el 12 de agosto de 2019 en varias ciudades capitales de México, y cuatro días después se realizó una segunda que llevó a miles de mujeres a las calles de la Ciudad de México en protesta de la violencia de género y los abusos que sufren de parte de las autoridades cuando piden ayuda. Esta marcha tuvo como elemento distintivo el lanzamiento de diamantina rosa y las pintas sobre monumentos emplazados en la vía pública. Durante la manifestación, la Columna del Ángel de la Independencia se cubrió con frases como "México feminicida" y "No
Figura 2 La estatua de
Edward Colston derribada y tirada al río, en Bristol, Foto: Ben Birchall/ Press Association, via Associated Press. New York 


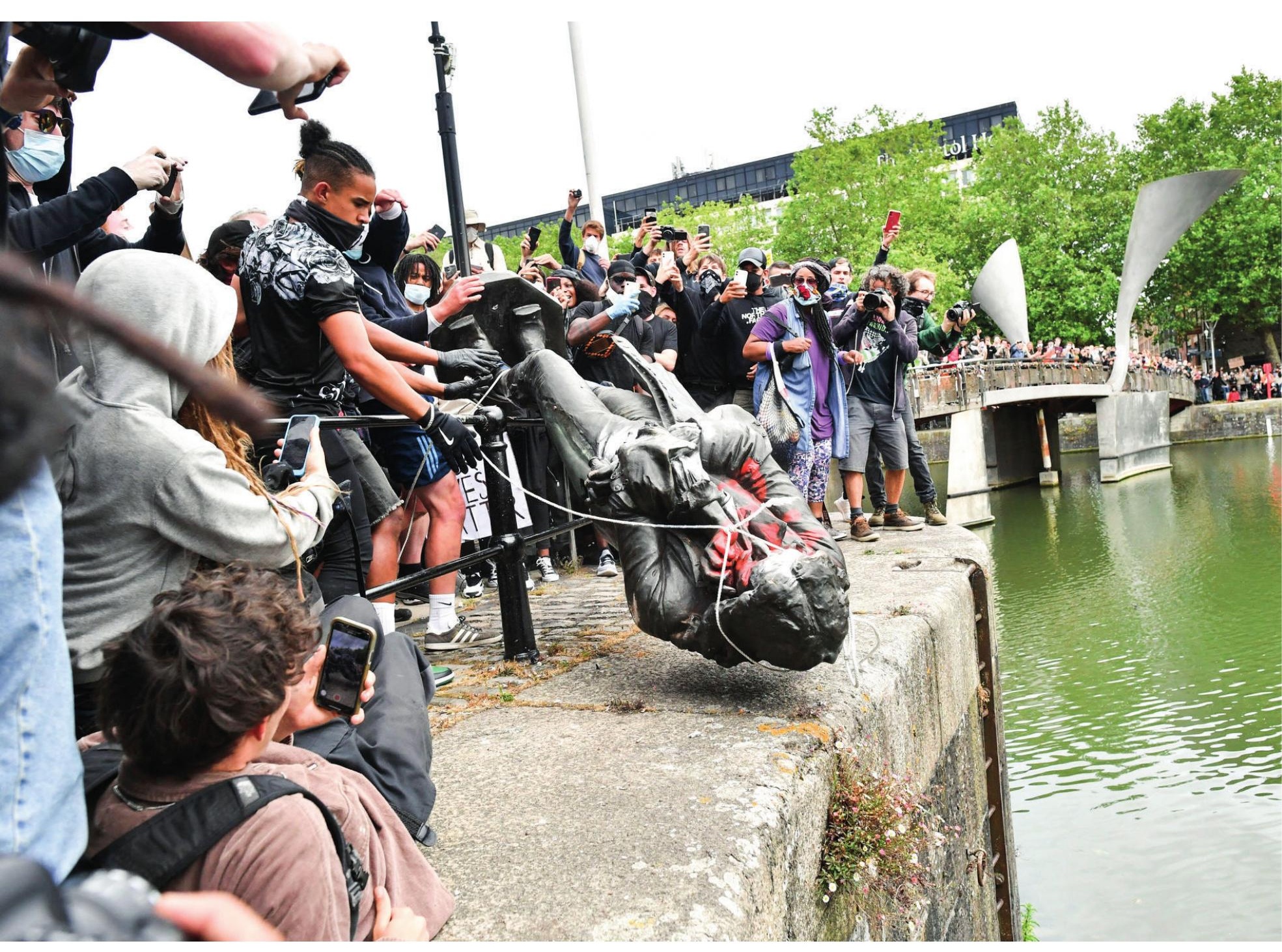

5 El Universal publicó el titular "Cierre del Ángel es por restauración, no por grafitis. La rehabilitación de los principales monumentos de la Ciudad de México coincidió con las pintas hechas durante la manifestación "No me cuidan, me violan", aclara Suárez del Real, al día siguiente." se va a caer, lo vamos a tirar" [Figura 3]. Un día después, la Columna fue cerrada y su rededor tapiado. El gobierno capitalino y la Secretaría de Cultura Federal comunicaron el inicio de los trabajos de restauración por los daños estructurales a consecuencia de los sismos de 2017 como explicación del cierre y de la instalación de la tapia, una maniobra que a todas luces buscaba restar visibilidad a la protesta y sus consecuencias. ${ }^{5}$ La prensa, lo mismo la más conservadora que la más liberal, construyó un discurso en el que las mujeres dejaron de ser víctimas para convertirse en victimarias, vandalizadoras del patrimonio. La marcha había incluido el bloqueo de la Av. Insurgentes y la ruptura de vidrios y pintas en la estación de Metrobús Insurgentes, pero nada fue más condenado que el grafiteo a la Columna de la Independencia. 


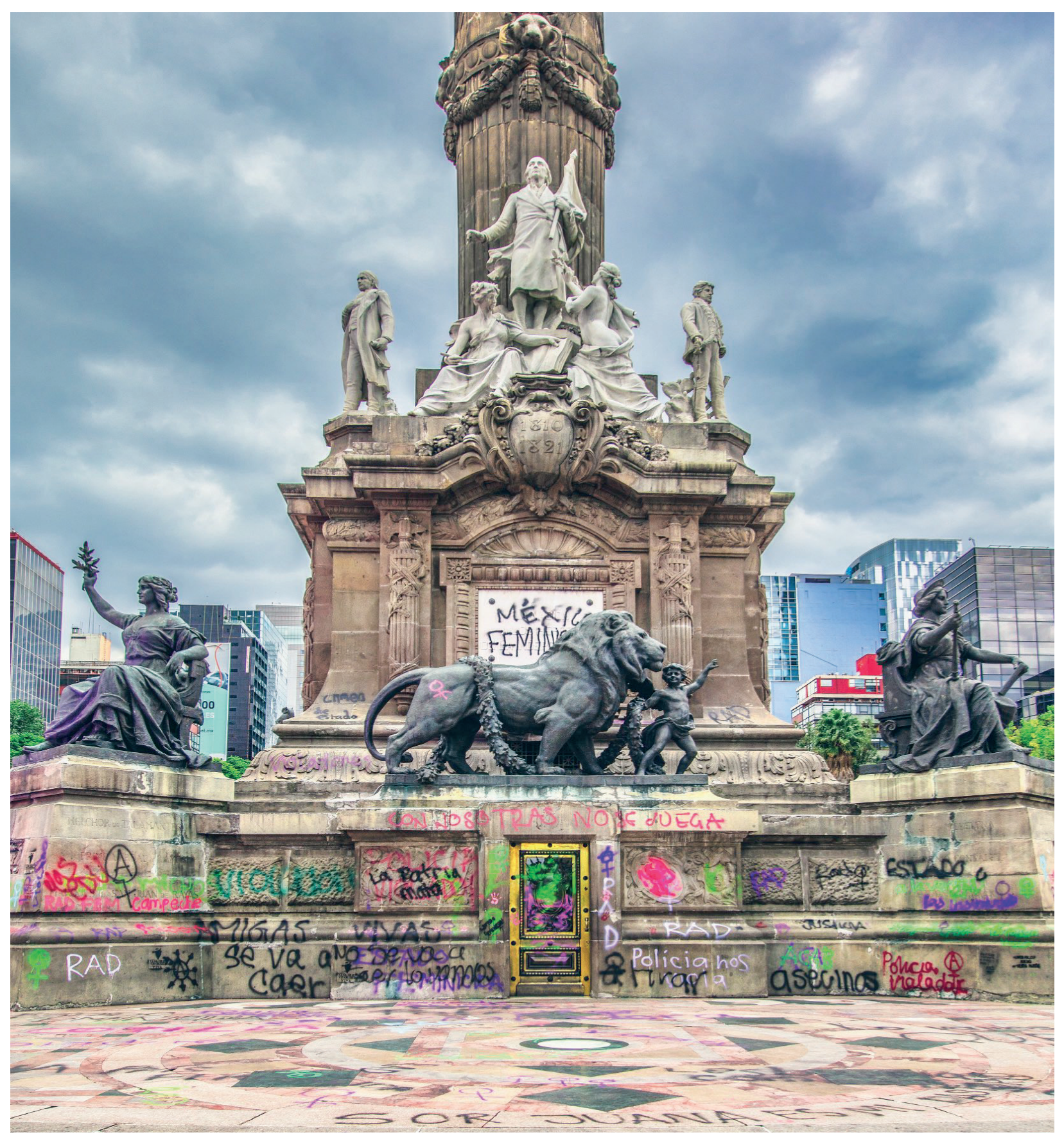

Figura 3

Pintas realizadas

sobre la Columna de

la Independencia

durante la marcha

del 16 de agosto

de 2019, en la

Ciudad de México.

Fotografía: Santiago

Arau (2019) cortesía

del autor via

twitter 


\section{CONCLUSIONES}

Las agresiones sobre los monumentos en los tres casos antes narrados surgen en contextos distintos y por razones particulares. La reflexión en conjunto sobre ellos sirve para entender y confirmar el desgaste que han sufrido las ideas sobre el patrimonio que habían sido adoptadas por los estados, la academia y gran parte de la sociedad hasta ahora. Puede ser que estos conceptos nunca hayan adquirido la estabilidad necesaria para enfrentarse a cambios tan drásticos y veloces como los que padecen las sociedades actuales.

En el caso de México, la Columna de la Independencia, conocida coloquialmente como El Ángel, es uno de los monumentos y sitios más emblemáticos de la capital mexicana y ha sido utilizado por mucho tiempo como su logotipo. Se transforma, cuando es necesario, en un lugar de festejos de todas índoles, manifestaciones políticas o de protesta y forma parte de la "marca" de la Ciudad de México que igual que otras ciudades del mundo se construye bajo un enfoque mercantilista. En esa idea, la Ciudad de México adoptó hace unos años el emblema "una ciudad con ángel".

Tal como otros monumentos conmemorativos contemporáneos, "El Ángel", al tiempo de su inauguración (1910) se impuso con una idea de nación a partir de un pasado selectivo y se definió como un monumento histórico, siguiendo lo ya dicho anteriormente, se trastocó en un bien objetivado, petrificado, cuya conservación y permanencia pasaron a ser incuestionables y superiores a cualesquiera otros intereses y necesidades de orden social. Entre otras opciones, la protesta escogió al Ángel como blanco de agresión por tratarse de un bien relevante para todos, de cierta manera puede hablarse de una provocación, un atrevimiento que vulnera lo que se suponía intocable.

Como explica Enrique Florescano, el patrimonio de una nación no es un hecho dado, sino que es una construcción histórica que involucra los intereses de las diversas clases que la integran (1997). Es por esta naturaleza artificial característica del patrimonio nacional que las estrategias para definirlo, conservarlo y difundirlo caen comúnmente en un acto de simulación, como si las clases y fracturas sociales, étnicas y de otros tipos no trascendieran al patrimonio y a su prestigio histórico y significación (García Canclini, 2009).Y es que no todos los bienes patrimoniales son significativos para todos, aunque se busque que así parezca, efectivamente se trata de formas diferentes y desiguales de apropiación social.

Las actitudes y posturas que señalaron y criminalizaron el grafiteo al Ángel son prueba, paradójicamente, de que el patrimonio es una creación artificial, una imposición y un instrumento de homogeneización. Entre otras declaraciones, se puede destacar la de Beatriz Gutiérrez Müller, presidenta honoraria del Consejo Asesor de la nueva Coordinación Nacional de Memoria Histórica y esposa del actual presidente de México: "Puede ser el caso de más injusticia en la historia del mundo, pero ese edificio o esa puerta es patrimonio de todos. Entonces es una agresión a todos, independientemente de la justicia o validez que tenga la protesta, que sea en el momento 
que sea, en el siglo que sea." (Proceso, 2019) Lo mismo en Chile, en cuanto a la destrucción de la escultura del conquistador Francisco de Aguirre, las declaraciones oficialistas volvieron a caer en el discurso del patrimonio como un bien representativo y de todos: "Como institución, lamentamos el daño al patrimonio y monumentos. Se trata de bienes públicos y comunes que son parte de un legado, de una historia y memoria colectiva que se desdibuja o se pierde" (EI Día, 26-10-2019), con lo que se desvirtúa el fondo del asunto, los reclamos legítimos y que incluso, en sí mismo, ofrece una retórica literal: la destrucción de un monumento histórico, impuesto y artificial, que signa un pasado que hoy es repudiado, para en su lugar instalar una objeto alegórico, que reivindica la idea de monumento en su sentido original: el de la conmemoración y el recuerdo que interesa a un grupo social, ¿cuál es el problema? ¿Por qué causa tanta conmoción el derribo?

Cabe preguntarse en qué medida la destrucción a esa y a otras muchas esculturas puede realmente trascender en el combate al racismo y al pensamiento colonialista subyacente en amplios sectores sociales, aunque es innegable que su derribo está implicado en una reconstrucción de la historia política de cada nación, dado que cualquier estatua-monumento plantada en las calles o plazas de una ciudad no puede interpretarse en la simpleza de un objeto ornamental, sino que está emparejado con el pensamiento político que lo instaló, y su permanencia material está condicionada a la vigencia de ese pensamiento y a las posibilidades de su derrocamiento.

Preguntamos iun monumento se puede revalorar, a partir de ciertas intervenciones? Incluso se puede hablar de él con un antes y un después, siendo el monumento mismo un factor para provocar el cambio. Supone un proceso y un resultado, pues simultáneamente es un proceso de producción, transmisión y reproducción. Las actuaciones destructivas que han sufrido muchas estatuas podrían incluso verse como intervenciones que reinventan y resignifican al monumento histórico: héroes decapitados, pedestales en los que figuran nombres y hechos históricos que no tienen nada sobre ellos, esculturas cubiertas de consignas. Estas nuevas versiones escultóricas pueden relacionarse con el concepto de contra-monumento (counter-monument) creado por James Young con respecto a aquellos monumentos que buscan recordar delitos y genocidios, (1992); parece que algunos van tomando ese papel. [Figura 4]

Frente a todos estos acontecimientos y ante el desconcierto e incertidumbre que suscitan, hay que resaltar el movimiento Restauradoras con Glitter en México, que conservando su posición crítica y solidaria con las mujeres víctimas lanzaron una propuesta. Este movimiento surgió tras las pintas sobre la Columna de la Independencia; es una colectiva integrada por casi 600 arquitectas, historiadoras, historiadoras del arte, arqueólogas y expertas en trabajos de conservación y 


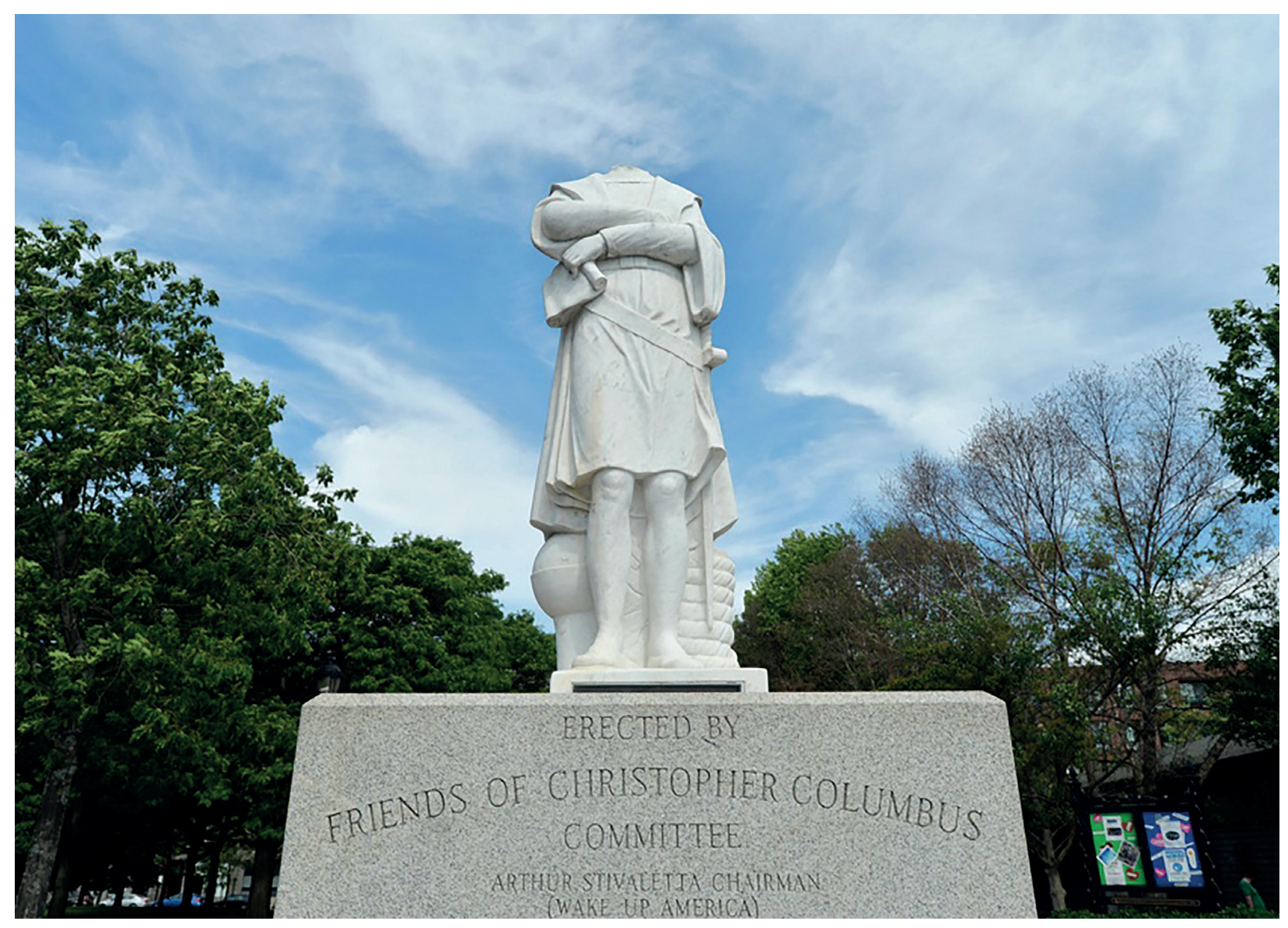

Figura 4

Estatua de

Cristóbal Colón

decapitada por el

movimiento "Black

Lives Matter",

$y$ que se ubica

en Christopher

Columbus Park en

Boston, Mass., EUA.

Fotografía: Joseph

Prezioso / AFP /

Getty Images restauración del patrimonio, quienes emitieron un comunicado para pedirle a las autoridades no remover las pintas hasta que no se diera atención al problema de violencia de género que existe en el país. Entre sus argumentos descuella la alta relevancia social, histórica y simbólica de las pintas, con lo que se da la posibilidad de un cambio en el discurso, diferenciando las pintas de las denuncias, que debieran ser documentadas minuciosamente por profesionales, con el fin de enfatizar y mantener viva la memoria colectiva sobre este acontecimiento y sus causas. Su propuesta incluye el exhorto a los colegas profesionales para no colaborar en la remoción de las pintas, hasta que el Gobierno Federal realice acciones necesarias para la solución, es decir, para garantizar la seguridad de las mujeres en territorio mexicano (Restauradoras con Glitter, 2019). Este grupo surgió en gran medida por la fuerte tendencia mediática que se concentró en las pintas y no en el fondo de las demandas, a pesar de su propia redacción: "tanto las columnas como los pedestales quedaron pintados con mensajes contra la violencia sexual y el machismo". La colectiva afirma que las 
pintas son una muestra justificada de desesperación ante la inacción sistemática para resolver la violencia que aqueja a las mujeres y que, en este caso, se dio con la legítima apropiación de un símbolo en un momento desesperado.

Los gobiernos, como menciona Thoreau, son el medio elegido por el pueblo para ejecutar su voluntad, aunque igualmente susceptibles de originar abusos y perjuicios antes de que el pueblo pueda intervenir (20 I4), por lo que en las reacciones ante las injusticias sociales puede decirse que el verdadero error es no reaccionar. Dado que el patrimonio es una representación de la institución y por ende del Estado, este se ha interpretado y se utiliza como una vía para comunicar las demandas de injusticia, porque lo deseable no es cultivar el respeto por la ley, si no por la justicia, hombres primero y ciudadanos después (Thoreau, 2014), por lo tanto, sería impensable que las nociones $y$ relaciones sobre $y$ con el patrimonio fueran fijas $y$ ajenas a las demandas de la sociedad.

Sectores de la sociedad contemporánea parecen ya no estar identificados con las intenciones del pasado, al menos no para quienes no han sido privilegiados del mismo. Debemos tomar en cuenta que no todos los monumentos son sobre la historia, sino sobre cierta versión de la historia. El valor que consigue el propio monumento para mantener viva la memoria y la presencia del pasado en el presente puede entrar en conflicto si no es aceptado o si su aceptación es polémica. La controversia que causa este tipo de actuaciones en contra del patrimonio, premeditadas o no, es tan fuerte que mueve más de lo que se podría alcanzar, es por ello que la reflexión y discusión del papel del patrimonio en los desencuentros sociales de la actualidad es forzosa. [Figura 5]

No se puede negar la trascendencia de la herencia cultural de una comunidad, de un pueblo o de una nación, o pensar que es posible actuar sobre su integridad sin que surjan confrontaciones, pero el hecho de que se den esas transgresiones, que son actos mayormente colectivos, contradicen los cánones del Estado actual, llaman a entender que las normas o principios que lo arropan ya no son válidos para la sociedad, o al menos para una parte de ella. Probablemente, si después de todos estos desencuentros se logra avanzar en materia de derechos humanos y civiles, estas intervenciones serán recordadas como históricas. La documentación y registro de las demandas, cuando se les analice e interprete, se convertirán en material necesario para la construcción de una sociedad en la que la herencia cultural jugó un papel trascendental como protagonista activa de un momento determinante.

Los usos sociales del patrimonio van de la mano de los procesos de transformación de la sociedad y sus actores pueden realizar cambios en su materialidad y así convertir a los bienes culturales en recursos. Dependiendo de la temporalidad, los significados sociales se modifican, pues como los referentes patrimoniales operan como 


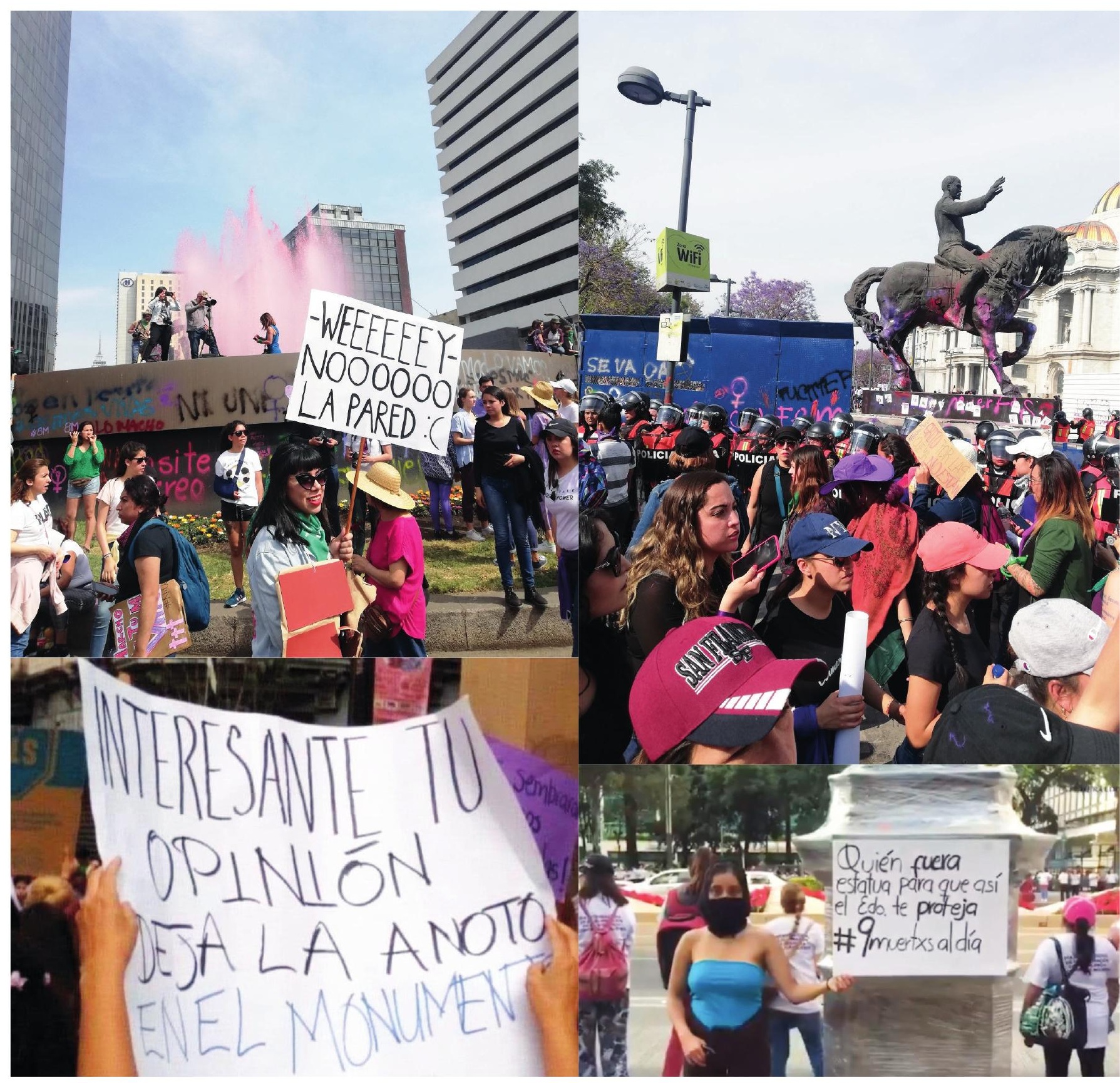


símbolos culturalmente creados son susceptibles de manipulación (Marcos, 20l0). Es por ello que se puede pensar que el monumento en esta nueva etapa de vida, debiera ser un receptor social, un espacio de nuevas apropiaciones, donde la manifestación tiene su lugar, en el que métodos tradicionales de la conservación tengan un espacio y un nuevo sentido, tales como las calas de prospección y registro de las pintas, para que éstas se presenten como mensajes focalizados, que de manera permanente pasen a formar parte de la historia del monumento, retomando este valor rememorativo para el que fueron creados, como una nueva capa que ayude a facilitar el recuerdo o evitar el olvido.

Finalmente, recordemos pues que la conservación de los monumentos, por medio de las instituciones ya sean públicas o privadas, es un fenómeno propio de la modernidad (Gónzalez-Varas, 20I4), por lo que la postura institucional, desde la academia y la conservación, es fundamental para interpretar e interceder en estas cuestiones. Comprendemos que no es un tema simple, tampoco ambicionamos dar una solución cuando ocurre el cruce de las protestas civiles con la herencia cultural, pero sí anhelamos que estos tópicos, aunque susciten escozor, sean tratados, pues son escenarios reales a los que hay que hacer frente. Es necesario tener una postura de apoyo, para que esta herencia, en su papel activo, en su proceso dinámico, en la conversación que tiene como parte de la sociedad, se pueda tratar desde un punto de vista horizontal y más que como especialistas, como integrantes de la sociedad.

Dejamos abierta la pregunta y la reflexión de repensar el patrimonio no de manera binaria, sino como el actor del cambio, siendo tal vez su intervención el camino a la transformación de la sociedad. Que no se trate de un acto vacío para que todos los monumentos terminen así, si no de una reflexión de la apropiación de nuestra herencia.

"Que los muros digan lo que la sociedad calla" Consigna popular 


\section{REFERENCIAS BILIOGRÁFICAS}

Actualidad. (2019). 09 noviembre 2019. Revisado en: https://actualidad. rt.com/actualidad/333079-perdida-gigantesca-incendio-universidad-chile BUCHANAN, L., BUI, Q. Y PATEL, J. (3 de julio de 2020). Black Lives Matter May Be the Largest Movement in the U.S. History. The New York Times. Recuperado de https://www.nytimes.com

CHOAY, F. (2007). Alegoría del patrimonio. Barcelona, España: Gustavo Gili. RIEGL, A. (1999). El culto moderno a los monumentos: Caracteres y origen. Madrid: Visor.García, C. N. (2009). La globalización imaginada. Barcelona: Paidós.

DELGADO, M. (2011) El espacio público como ideología, Madrid: Catarata El Día. (2019). 26 de octubre 2019. Revisado en: http://www. diarioeldia.cl/ magazine/alcalde-no-removera-estatua-mujer-diaguita-se-abre-dialogo

FLORESCANO, E. (1999). El patrimonio nacional. Valores, usos, estudios y difusión. En E. Florescano, El patrimonio nacional de México I (págs. 15-27). México: Consejo Nacional para la Cultura y las Artes, Fondo de Cultura Económica.

GARCíA C. N. (1999). Los usos sociales del Patrimonio Cultural. En E. A. Criado, Patrimonio etnológico: nuevas perspectivas de estudio (págs. 1633). España: Junta de Andalucía, Instituto Andaluz del Patrimonio Histórico. GARCÍA, C. N. (2009). La globalización imaginada. Barcelona: Paidós.

GONZÁLEZ-VARAS, I. (2014). Las ruinas de la memoria. Ideas y conceptos para una (im)posible teoría del patrimonio cultural. México, S.XXI Editores Infobae (2019). 08 noviembre 2019. Recuperado en: https://www.infobae. com/america/america-latina/2019/11/08/a-tres-semanas-del-inicio-de-lasprotestas-miles-de-jovenes-se-mantienen-en-las-calles-de-chile-contra-elgobierno-de-pinera/

MARCOS, J. (2010). El patrimonio como representación colectiva. La intangibilidad de los bienes culturales. En Gazeta de Antropología N²6/1, artículo 19, Universidad de Granada, recuperado de http://hdl.handle. net/10481/6799 el 17 de noviembre de 2019

Proceso. (2019). 27 agosto 2019. Revisado en: https://www.proceso.com. mx/597371/pintas-a-monumentos-historicos-son-una-agresion-a-todos-dice-gutierrez-muller

Restauradoras con Glitter (2019) Carta abierta dirigida al Presidente de la República Mexicana Lic. Andrés Manuel López Obrador y la Jefa de Gobierno de la CDMX Dra. Claudia Sheinbaum el 21 de agosto de 2019. Recuperada de https://www.facebook.com/restauradoras.glitterMX

The New York Times. (2020). 08 junio 2020. Recuperado en: https://www. nytimes.com/2020/06/08/world/europe/edward-colston-statue-britain-racism.html

The New York Times. (2020). 03 julio 2020. Revisado en: https://www.nytimes.com/interactive/2020/07/03/us/george-floyd-protests-crowd-size.html THOREAU, H. (2014). Desobediencia civil y otros textos. México, Universidad Autónoma de Morelos.

UNESCO. (2014). Indicadores UNESCO de Cultura para el Desarrollo. París. YOUNG, J. (1992). The Counter-Monument: Memory against Itself in Germany Today. Critical Inquiry, 18(2), 267-296. 